\title{
Transformação carcinomatosa de endometriose retroperitoneal
}

\section{Carcinomatous transformation of retroperitoneal endometriosis}

\author{
João Augusto dos Santos Martines ${ }^{a}$, Brenda Margatho Ramos Martines ${ }^{a}$, Daniel Roberto Garzi ${ }^{b}$, \\ Silvana Maria Lovisoloa ${ }^{a}$ Cornélius Mitteldorfa, Paulo Francisco Ramos Margaridoa
}

Martines JAS, Martines BMR, Garzi DR, Lovisolo SM, Mitteldorf C, Margarido PFR. Transformação carcinomatosa de endometriose retroperitoneal. Autopsy Case Rep [Internet]. 2011;1(2):31-40.

\section{RESUMO}

\begin{abstract}
Os autores apresentam o caso de uma paciente de 45 anos de idade, portadora de dor abdominal crônica, sendo evidenciada massa retroperitoneal cuja biopsia por agulha revelou tratar-se de endometriose. Submetida a ooforectomia bilateral. A paciente evoluiu, durante 4 anos, sem controle do quadro álgico, com perda de peso e aumento das dimensões da massa tumoral. A exérese cirúrgica total da massa tumoral não foi possível devido às aderências às estruturas vasculares. O pós-operatório foi complicado com quadro séptico evoluindo a óbito. O resultado anatomopatológico fornecido pela autópsia foi de adenocarcinoma de padrão endometrióide.
\end{abstract}

Unitermos: Endometriose; Adenocarcinoma; Neoplasias; Espaço retroperitoneal.

\section{ABSTRACT}

The authors present a case of a female patient 45 years old with chronic abdominal pain and a retroperitoneal tumor mass which showed the diagnosis of endometriosis by fine needle biopsy. Bilateral oophorectomy was performed. The patient remained symptomatic,the next four years, with pain and weight loss and new diagnostic images revealed tumor mass growth. Radical surgical treatment was impracticable due to tumor adhesions to major vascular structures. Post operatory was troublesome with septic complications evolving to death. The autopsy results showed the diagnosis of endometrioid adenocarcinoma.

Keywords: Endometriosis; Adenocarcinoma; Neoplasm; Retroperitoneal space.

\footnotetext{
${ }^{a}$ Hospital Universitário - Universidade de São Paulo, São Paulo/SP - Brasil.

$\mathrm{b}^{\mathrm{b}}$ Instituto do Coração - Hospital das Clínicas da Faculdade de Medicina - Universidade de São Paulo, São Paulo/SP - Brasil.

Copyright (C) 2011 Autopsy and Case Reports - Este artigo de Acesso Aberto é distribuído pelos termos do Creative Commons Attribution NonCommercial License (http://creativecommons.org/licenses/by/3.0/ ) que permite livre uso não-comercial, distribuição e reprodução em qualquer meio, desde que os artigos sejam devidamente citados.
} 


\section{INTRODUÇÃO}

A endometriose foi descrita pela primeira vez por Roktansky, em 1869, que observou em tecido de necrópsia material de aspecto histológico e funcional semelhante ao endométrio fora da cavidade uterina. ${ }^{1}$ Apresenta prevalência estimada entre 5 e $15 \%$ das mulheres em idade reprodutiva ${ }^{2}$ e sua etiologia ainda é incerta. Sua patogênese tem sido explicada por teorias que apontam principalmente a multi causalidade, fatores genéticos, imunológicos, e disfunção endometrial. ${ }^{1}$ Os sítios mais freqüentemente envolvidos são os ovários, fundo de saco anterior e posterior, folheto posterior do ligamento largo, ligamento uterossacro e cólon sigmóide. ${ }^{3}$

Embora a endometriose não seja classificada como doença pré-maligna, estudos têm encontrado aumento da incidência de câncer ovariano em mulheres com endometriose, bem como tem verificado aumento da incidência de endometriose em mulheres com câncer de ovário. ${ }^{4,5}$ Estudos retrospectivos têm sugerido que pode haver associação entre endometriose e risco aumentado de câncer de ovário. Brinton et al. $^{6}$ relataram que mulheres com diagnóstico de endometriose apresentam taxa de incidência de câncer de ovário de 2,48 (IC 95\%, $1,3-4,2)$ quando comparadas com mulheres sem a doença. Entretanto, pelo fato da endometriose ser relativamente comum, algumas vezes não fica claro se a endometriose sofreu a transformação maligna ou simplesmente coexiste com o câncer. ${ }^{7}$ Para se confirmar o diagnóstico de transformação maligna de um foco endometriótico, primeiramente deve-se excluir que a suposta lesão não seja metástase de uma outra neoplasia primária. ${ }^{8}$ Os tipos de câncer de ovário mais comumente associados à endometriose são os carcinomas endometrióide e o de células claras. ${ }^{9}$

Apresentamos a seguir relato de caso de paciente com endometriose retroperitoneal com transformação para adenocarcinoma, ressaltando a importância dos achados clínicos e radiológicos desta rara evolução.

\section{Relato do Caso}

Paciente do sexo feminino com 45 anos de idade foi admitida no Hospital Universitário da Universidade de São Paulo com história de dor abdominal há 2 semanas, sem melhora com o uso de medicação analgésica. Apresentava aumento do volume uterino (190 $\mathrm{cm}^{3}$ ao ultrassom transvaginal) e CA-125 > $200 \mathrm{U} / \mathrm{mL}$, sendo feita hipótese diagnóstica de adenomiose/endometriose pélvica. Submetida a histerectomia para tratamento da dismenorréia. Não se evidenciou presença de endometriose no estudo histopatológico. A paciente apresentava antecedente obstétrico de 2 gestações e 2 partos normais e antecedente de dismenorreia.

Evoluiu com queixa de perda de peso e dor abdominal em hipocôndrio esquerdo motivando vários atendimentos de Pronto Socorro.

O exame radiológico contrastado do trânsito intestinal evidenciava deslocamento gástrico com alargamento da pequena curvatura (Figura 1).

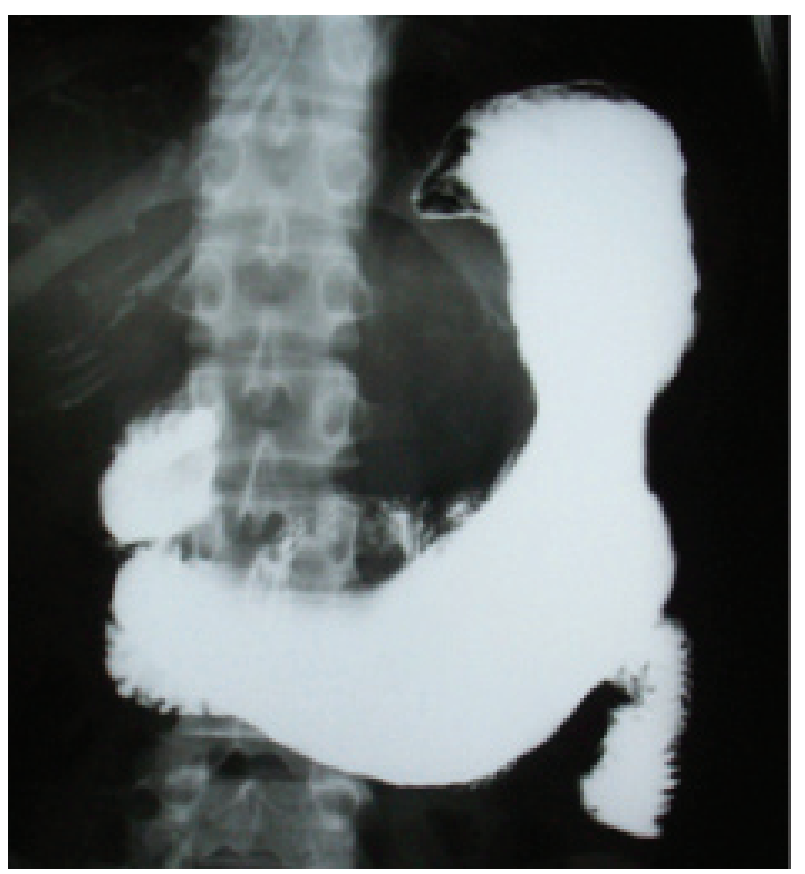

Figura 1 - Exame radiológico contrastado do transito intestinal mostrando deslocamento gástrico com alargamento da pequena curvatura. 
Nesta ocasião foi evidenciada em exame ultrassonográfico imagem nodular para-aórtica próxima ao tronco celíaco. A Ressonância Magnética (RM) do abdome nesta época revelou massa retroperitoneal heterogênea de $6,0 \times 5,0 \times 3,0 \mathrm{~cm}$, que foi abordada por punção guiada, revelando tratarse de endometriose.

Optado por ooforectomia bilateral terapêutica. O exame histopatológico revelou: Endometriose estromal e glandular de padrão misto em tubas uterinas e cistos serosos para-tubários.

Manteve a queixa de dor em hipocôndrio esquerdo, acompanhada de náuseas e vômitos. Ao ultrassom apresentava persistência da massa cística para-aórtica. Submetida à laparotomia onde foi realizada exérese parcial do cisto, devido à sua intimidade com a aorta, tronco celíaco e vasos mesentéricos. O exame anatomopatológico revelou cisto endometriótico com hemorragia.

Após um ano foi realizada nova tomografia computadorizada que acusava lesão residual retroperitoneal. Submetida à eco endoscopia com punção por agulha fina. Concluiu-se através da análise do aspirado que os achados citológicos correspondiam a hipótese clínica de endometrioma, porém devido a presença de muita necrose no material, não se excluía a possibilidade de neoplasia epitelial bem diferenciada. Mantida sob tratamento clínico com controle parcial da dor e das náuseas.

Exame de controle por RM (Figura 2), após um ano, mostrou aumento das dimensões da massa retroperitoneal, descrita como lesão expansiva complexa, sólida com áreas císticas de permeio, que apresentava ampla superfície de contato com o pâncreas, aorta, tronco celíaco, artéria mesentérica superior e veias esplênica e renal esquerda.
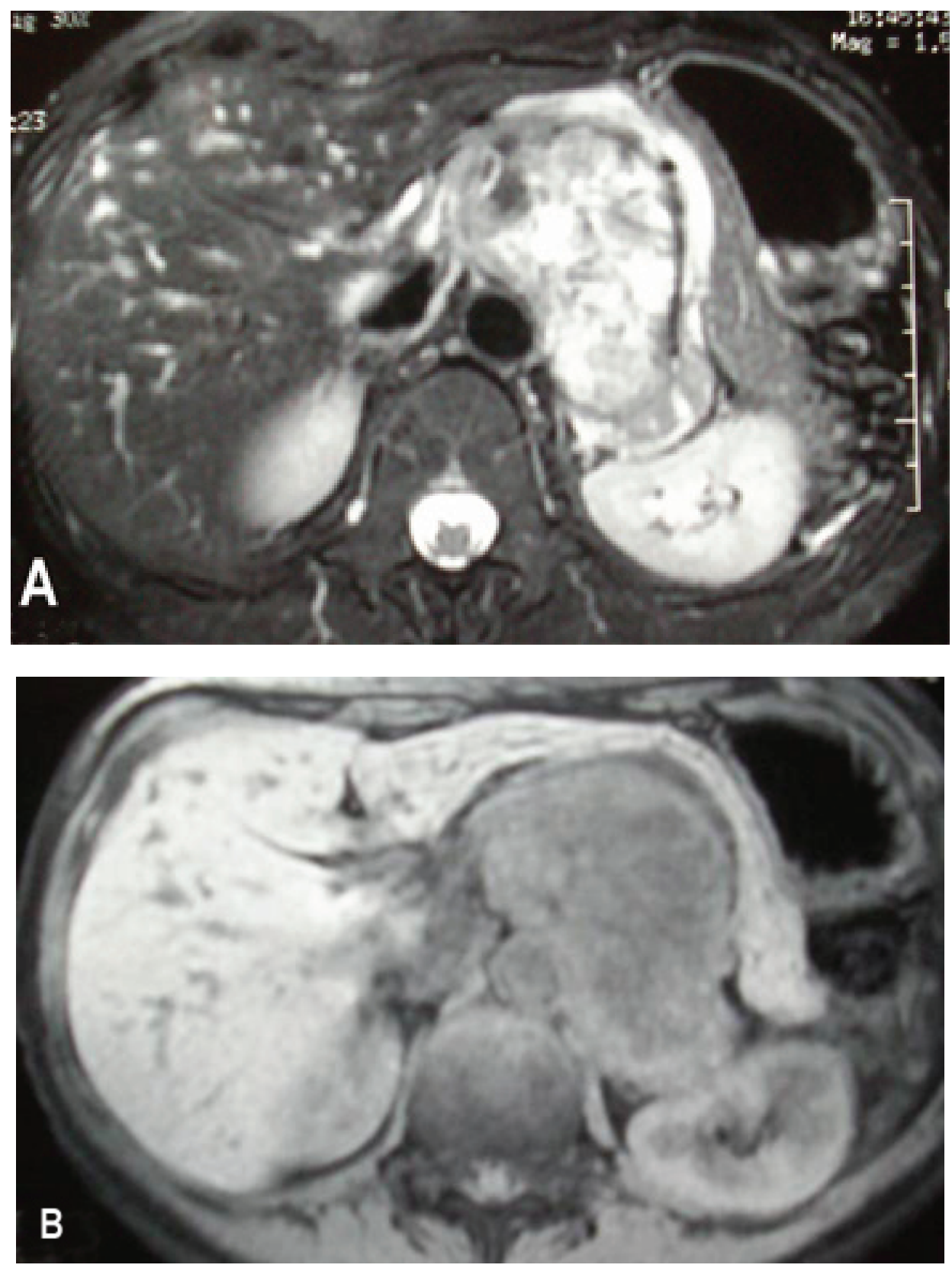


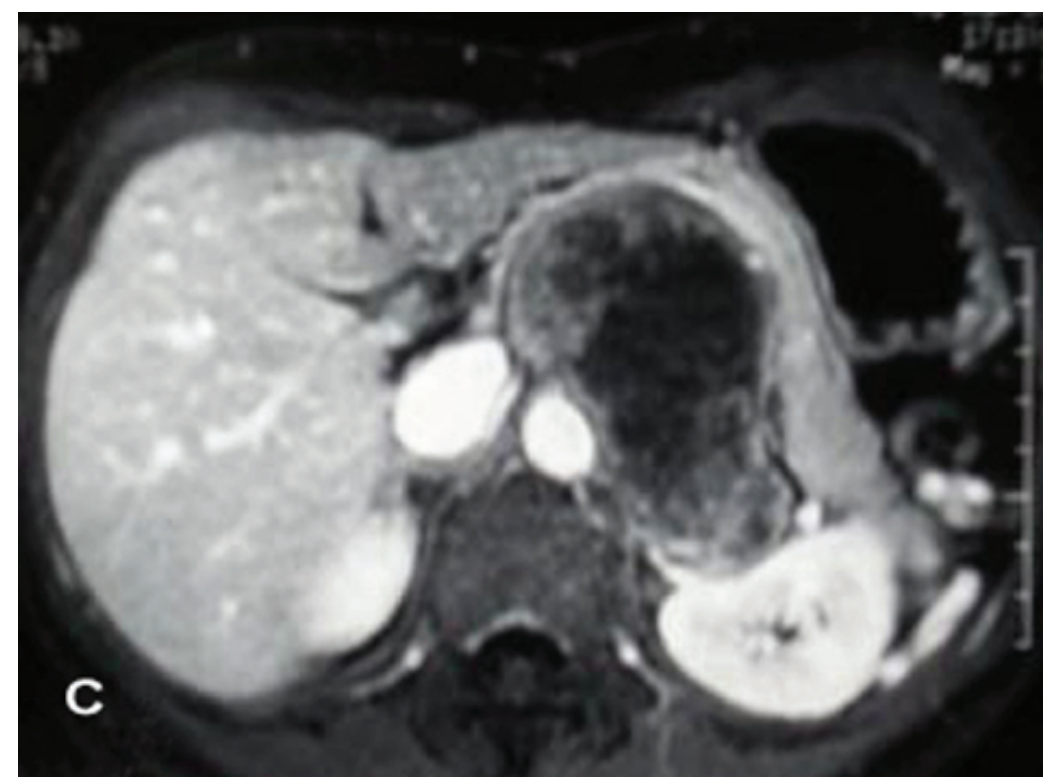

Figura 2 - Imagem de RM com: A - seqüência ponderada em T2, B - T1 sem contraste e C - T1 após gadolíneo endovenoso, evidenciando volumosa massa heterogênea, com áreas sólidas periféricas de isossinal em T2 e T1 com realce pós-contraste associado a áreas centrais de hipersinal em T2 e hipossinal em T1, sem realce pelo contraste, sugerindo cistos e/ou focos de necrose/liquefação. A massa se localiza no retroperitônio em região para-aórtica à esquerda, deslocando a veia esplênica e pâncreas anteriormente.

Após 4 anos da primeira abordagem cirúrgica da massa retroperitoneal, a paciente apresentava-se emagrecida (I.M.C. $=17$ ) com piora da dor, apresentando náuseas, vômitos e inapetência. O exame físico evidenciou massa endurecida, em topografia de epigástrio, aderida a planos profundos.

Foi submetida à nova laparotomia na tentativa da retirada do tumor intra-abdominal, sendo achada massa endurecida de $15 \mathrm{~cm}$, aderida a estruturas do retroperitônio. Realizada gastrectomia a dois terços, esplenectomia e pancreatectomia corpo-caudal como tática de acesso à massa e com o intuito de melhorar o esvaziamento gástrico. No entanto, a massa era irressecável devido a aderência aos vasos mesentéricos, tronco celíaco e aorta.
Evoluiu no pós-operatório com deiscência da anastomose e peritonite, evoluindo a óbito 45 dias após a cirurgia, por choque séptico.

\section{AUTÓPSIA}

À abertura do cadáver foi observada massa retroperitoneal irregular (Figura 3) medindo 15,0 cm no maior eixo, aderida à aorta, ao tronco celíaco e vasos mesentéricos. Aos cortes, a massa mostra área central de coloração castanho-amarelada de aspecto neoplásico medindo $6,0 \mathrm{~cm}$ no maior eixo com focos de necrose e de hemorragia, parcialmente circunscrito por cápsula fibrosa (Figura 4).

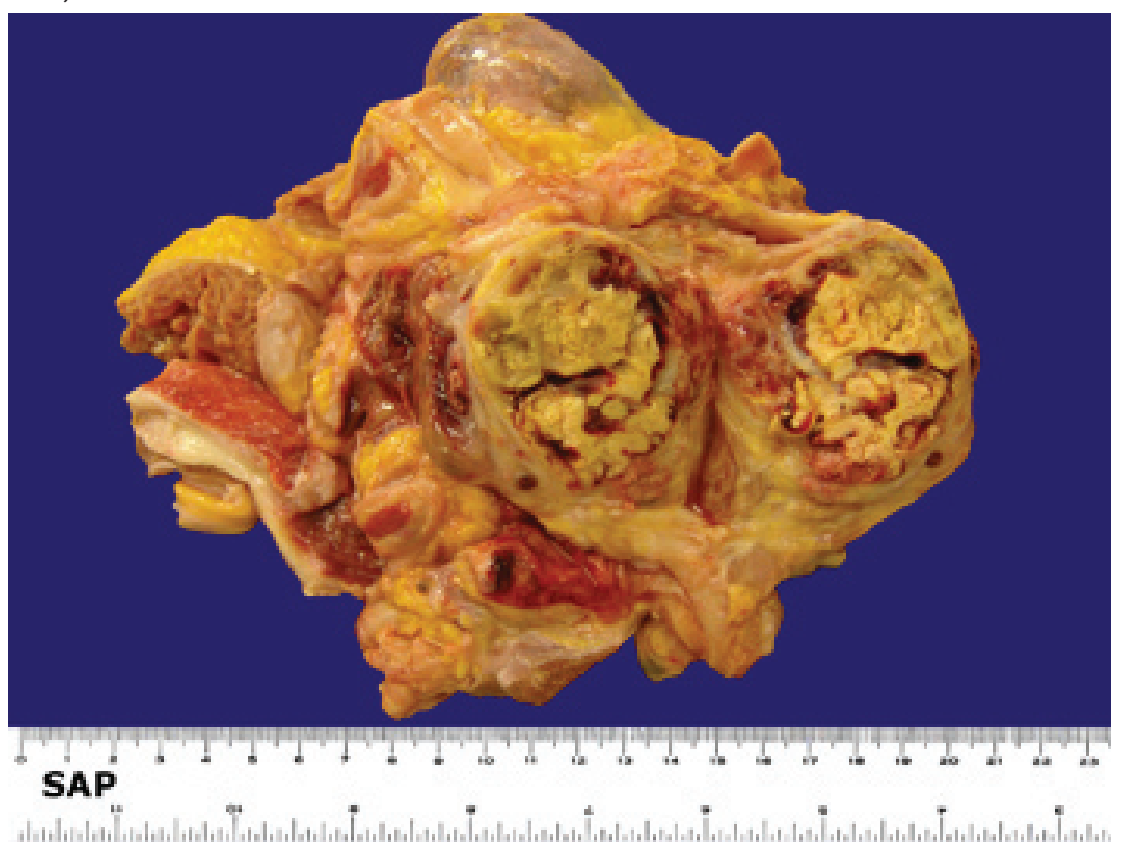

Figura 3 - Massa retroperitoneal (15,0 cm no maior eixo). 


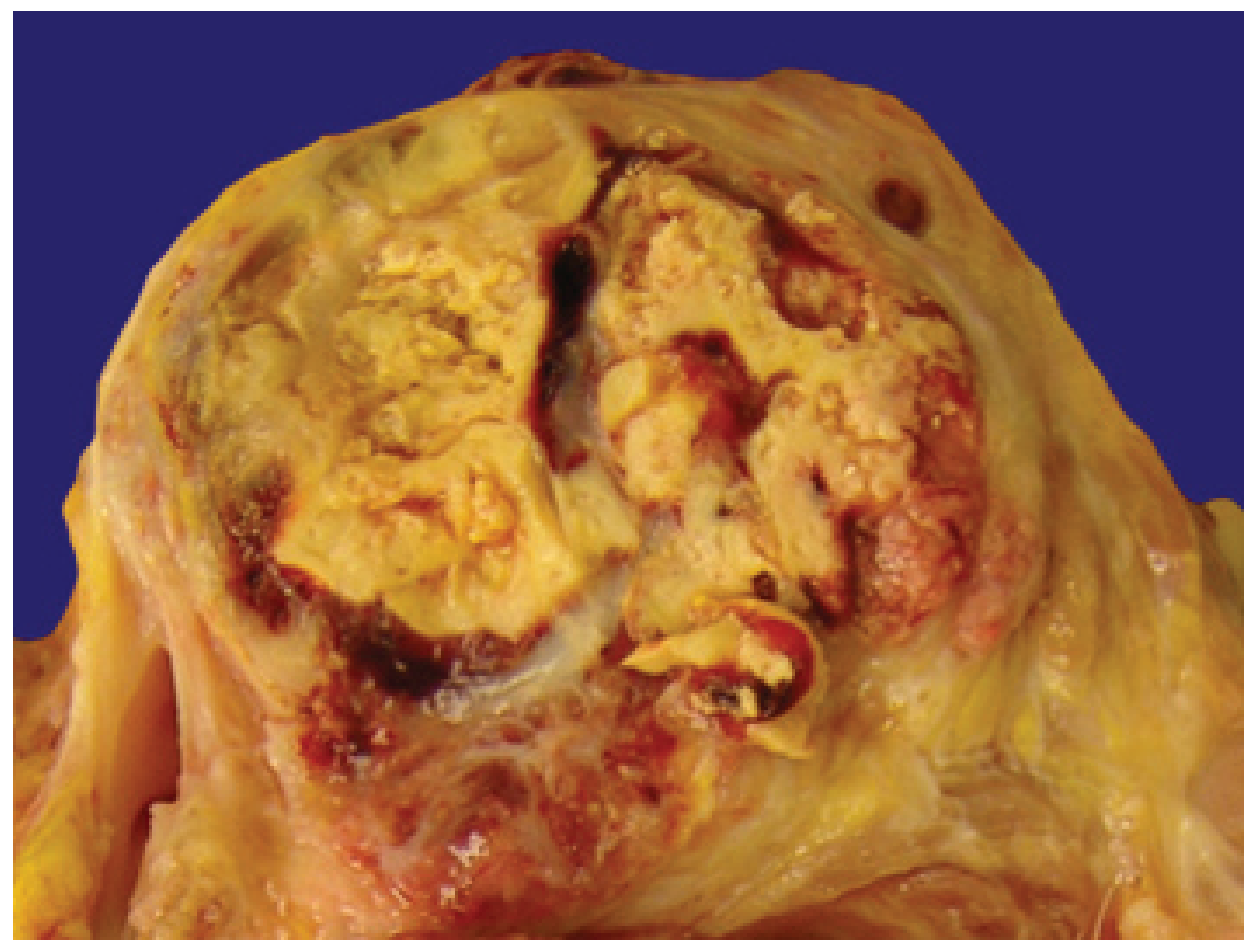

Figura 4 - Detalhe da área neoplásica (6,0 cm no maior eixo) da massa retroperitoneal: tecido castanho-amarelado de limites imprecisos com aspecto infiltrativo com focos de necrose e de hemorragia, circunscrita por tecido fibroso esbranquiçado de aspecto capsular.

Ausência do baço, do corpo e cauda do pâncreas, do antro gástrico (gastrectomia parcial com reconstrução em Y de Roux), dos ovários, das tubas uterinas e do útero (salpingo-ooforectomia bilateral e histerectomia).

Quatro anos antes do óbito, a paciente ha- via sido submetida a laparotomia com retirada de parte da parede da massa retroperitoneal cujo laudo anatomopatológico evidenciou cisto endometriótico com hemorragia, reação histiocitária xantomatosa e gigantocelular a fendas de cristais de colesterol (Figura 5).

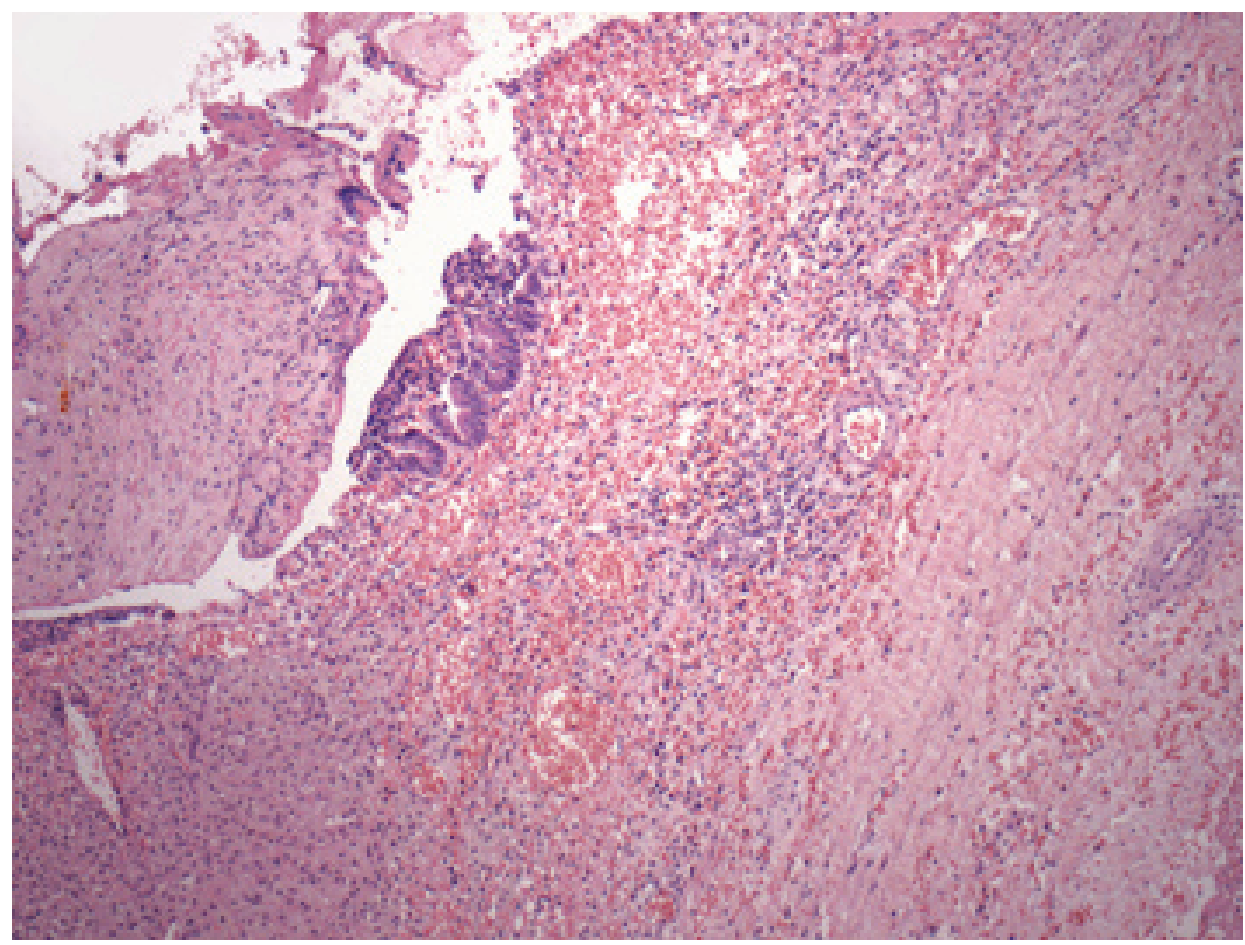

Figura 5 - Fotomicrografia (H\&E 100X) - Cisto endometriótico com hemorragia, reação histiocitária xantomatosa e gigantocelular a cristais de colesterol, produto de laparotomia realizada 4 anos antes do óbito. 
O exame histopatológico da massa retroperitoneal evidenciou adenocarcinoma caracterizado pela proliferação neoplásica de padrão glandular predominantemente endometrióide (Figuras 6,7) com áreas focais de padrão glandular seroso pa- pilífero (Figura 8), que infiltra área fibrosa rica em colágeno (cápsula fibrosa do cisto endometriótico retroperitoneal) (Figura 9), com necrose central (Figura 10).

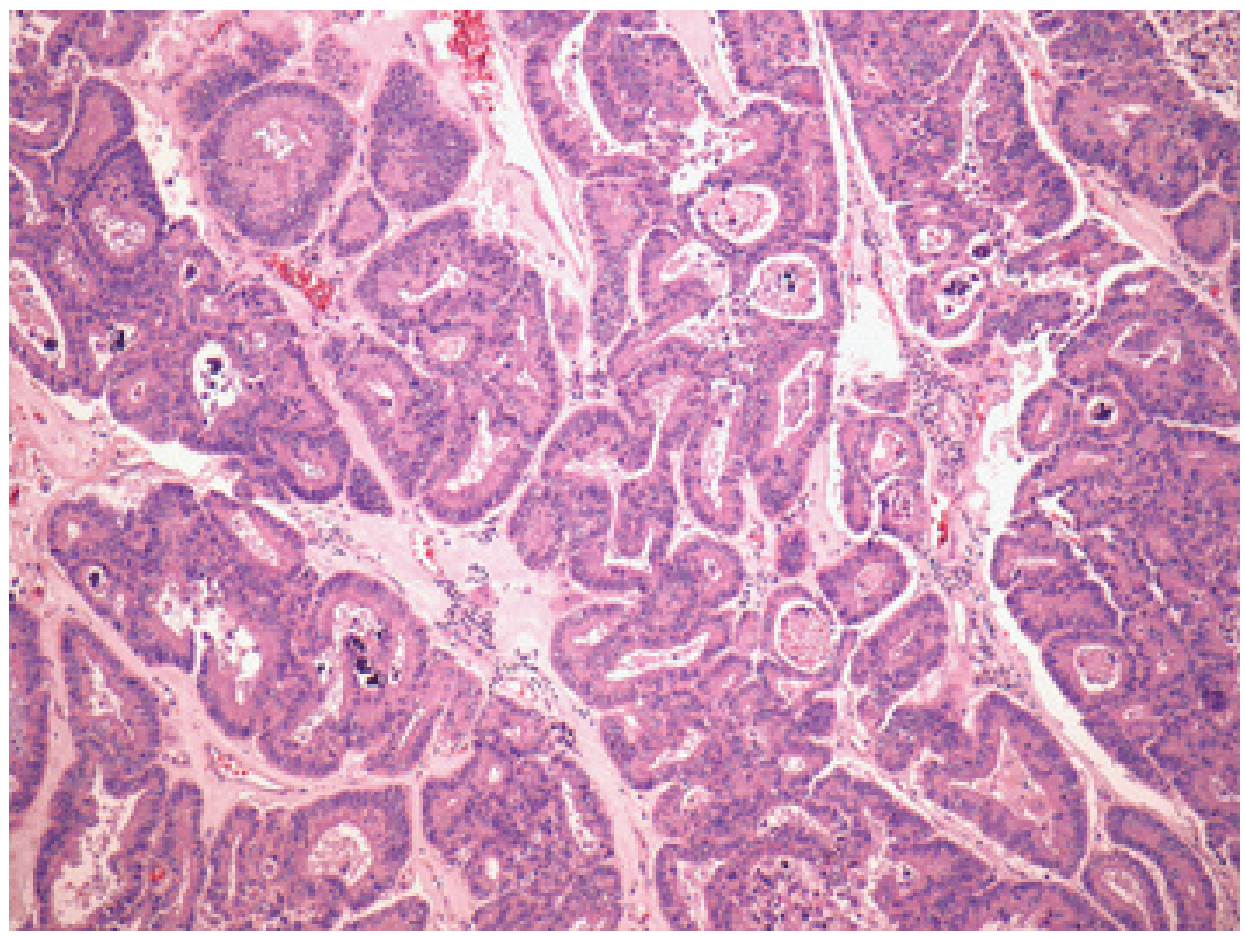

Figura 6 - Fotomicrografia (H\&E 100X) - Adenocarcinoma de padrão endometrióide com focos de calcificação.

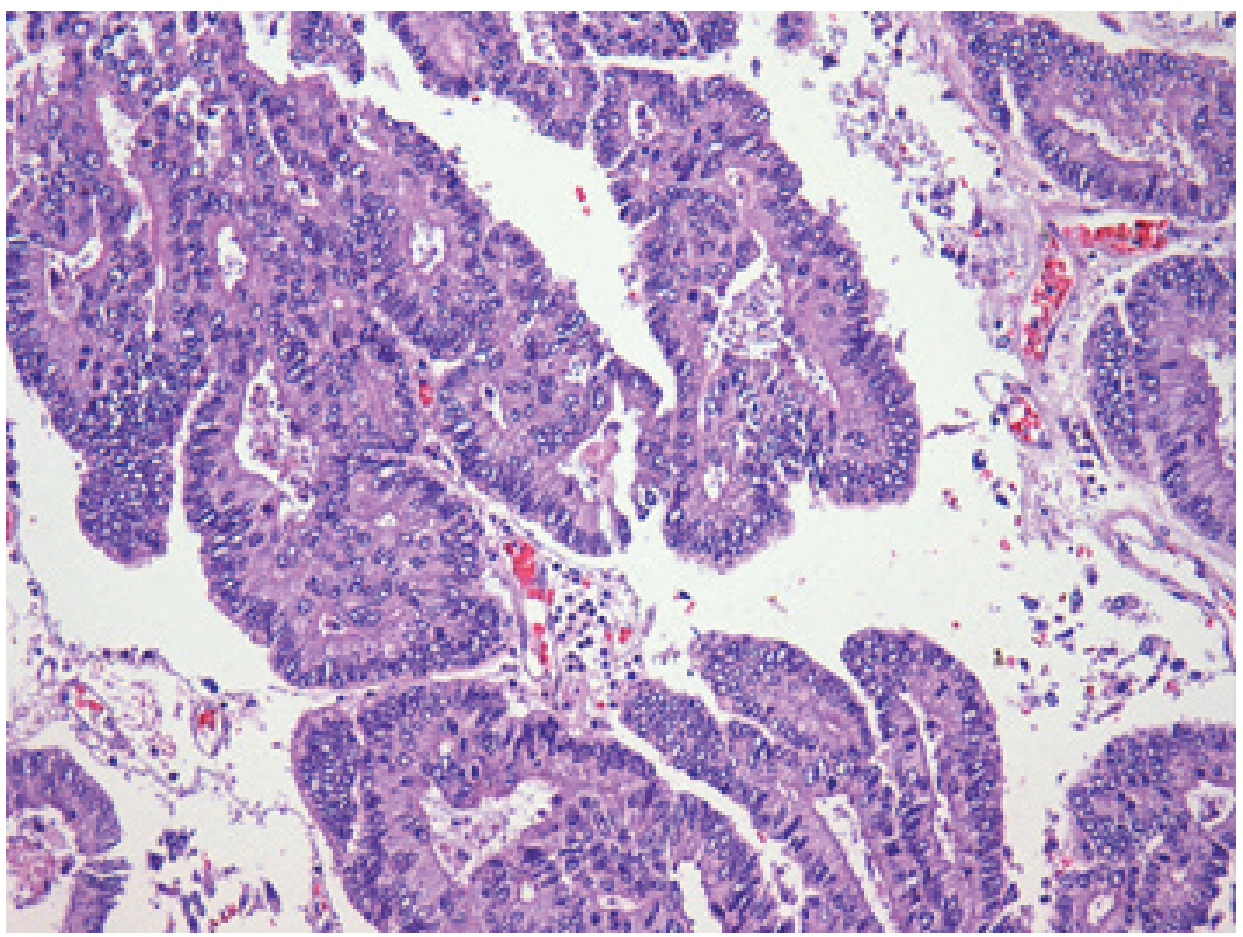

Figura 7- Fotomicrografia (H\&E 200X) - Adenocarcinoma de padrão endometrióide. 


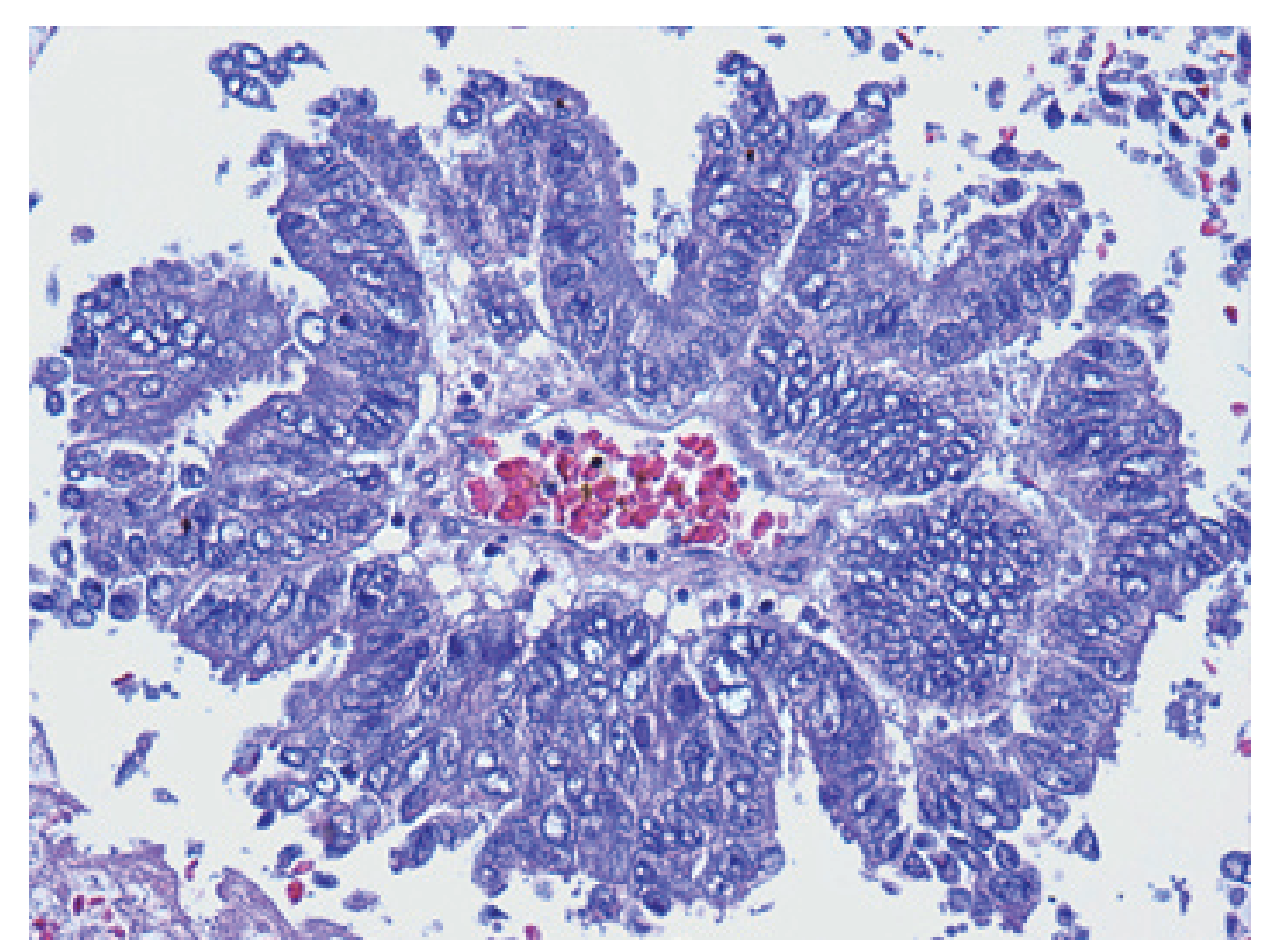

Figura 8 - Fotomicrografia (H\&E 400X) - Área do adenocarcinoma de padrão papilífero seroso com eixo fibro-conjuntivo central e capilar sanguíneo com hemácias.

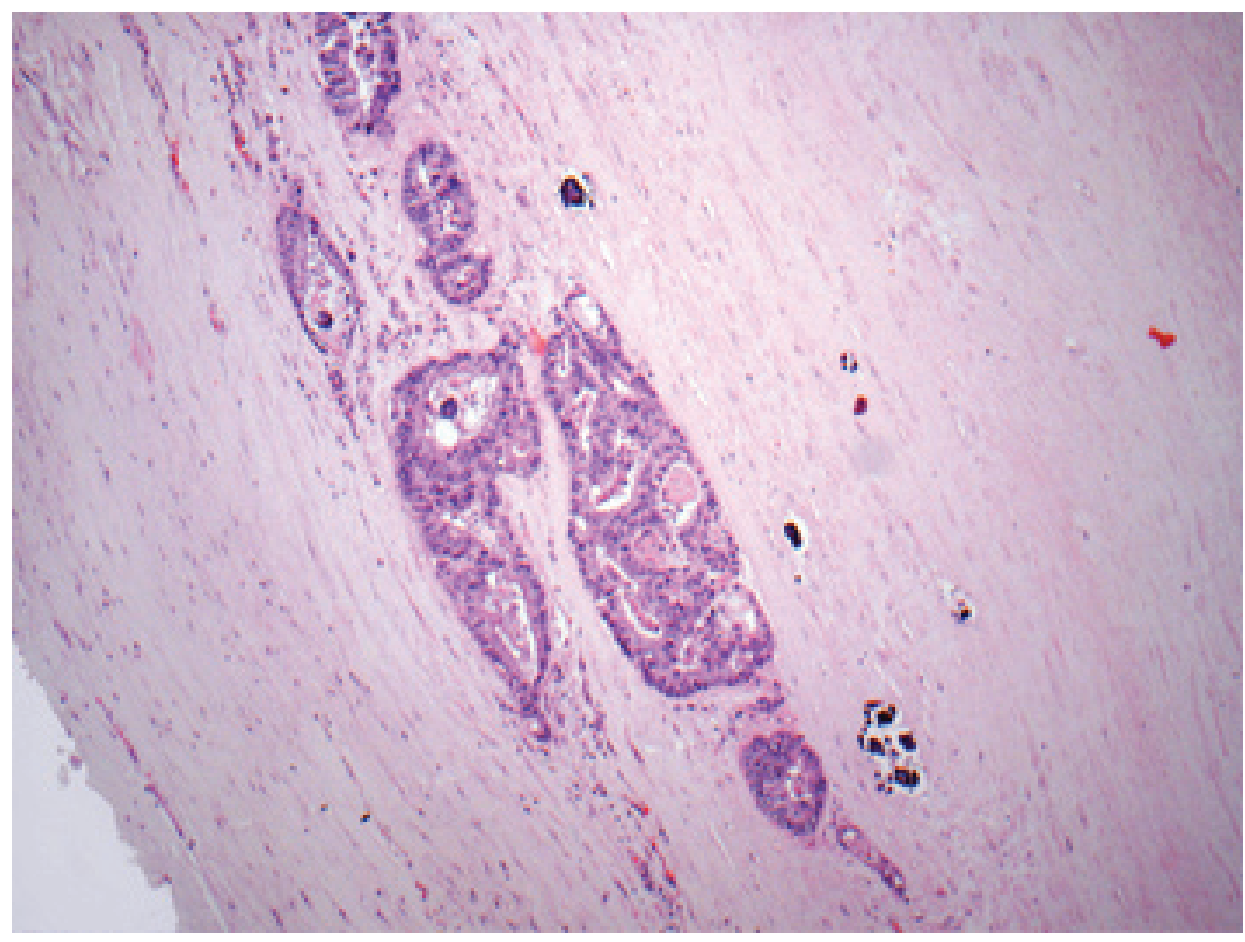

Figura 9 - Fotomicrografia (H\&E 100X) - Infiltração neoplásica da cápsula fibrosa com focos de calcificação. 


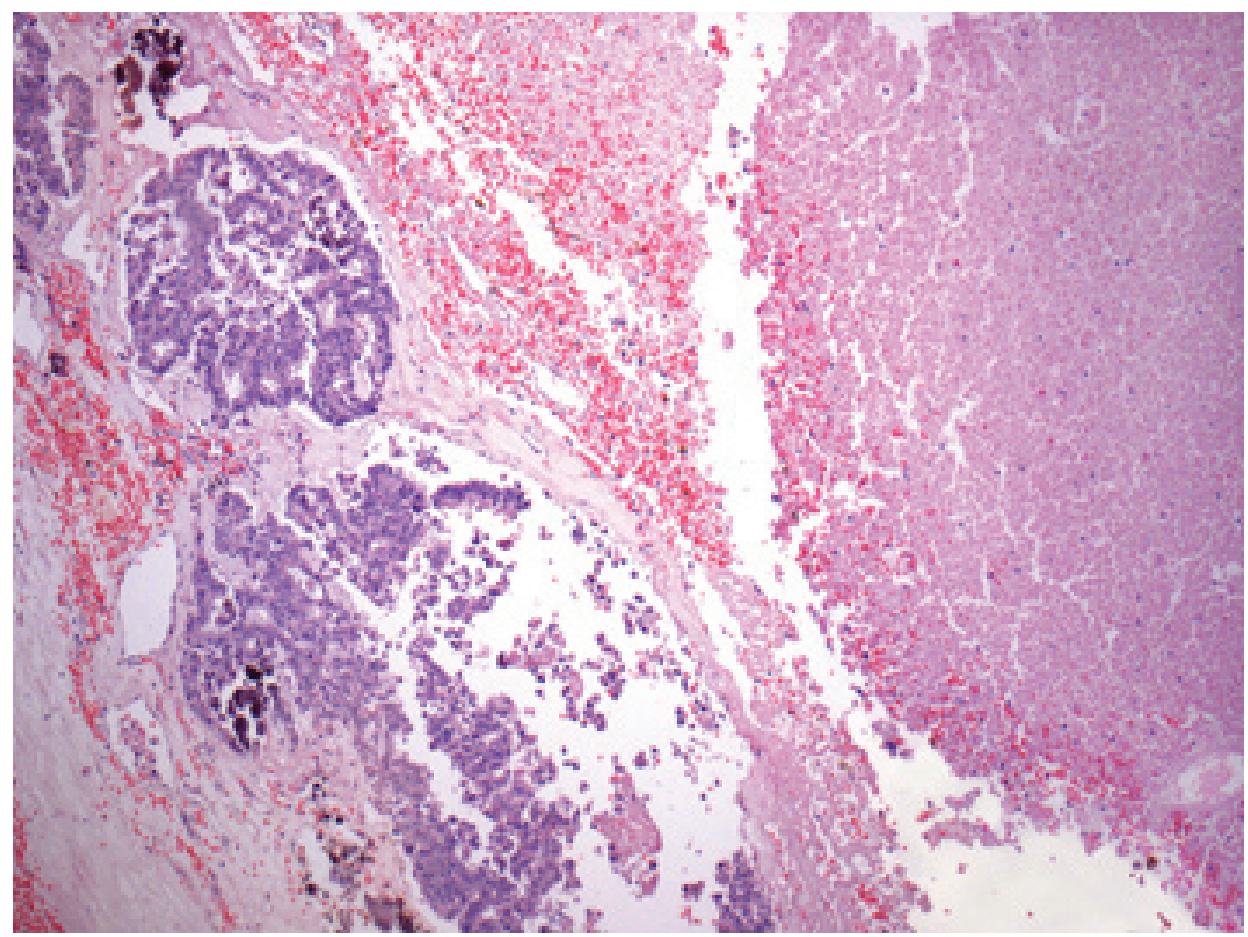

Figura 10 - Fotomicrografia (H\&E 100X) - Cisto endometriótico com área central necrótica (à direita) e infiltração neoplásica da cápsula fibrosa com focos de calcificação.

O diagnóstico diferencial, nesta localização retroperitoneal, deve ser feito com mesotelioma peritoneal epitelióide. Segundo Ordóñez ${ }^{17}$, o anticorpo monoclonal Ber-EP4, negativo no mesotelioma e positivo no adenocarcinoma é considerado um dos mais úteis marcadores para esta distinção.
O exame imuno-histoquímico da área neoplásica deste caso foi difusamente positivo para Ber-EP4 (Figura 11) e negativo para CK-20 e CEA excluindo o diagnóstico diferencial com adenocarcinoma gastrointestinal.

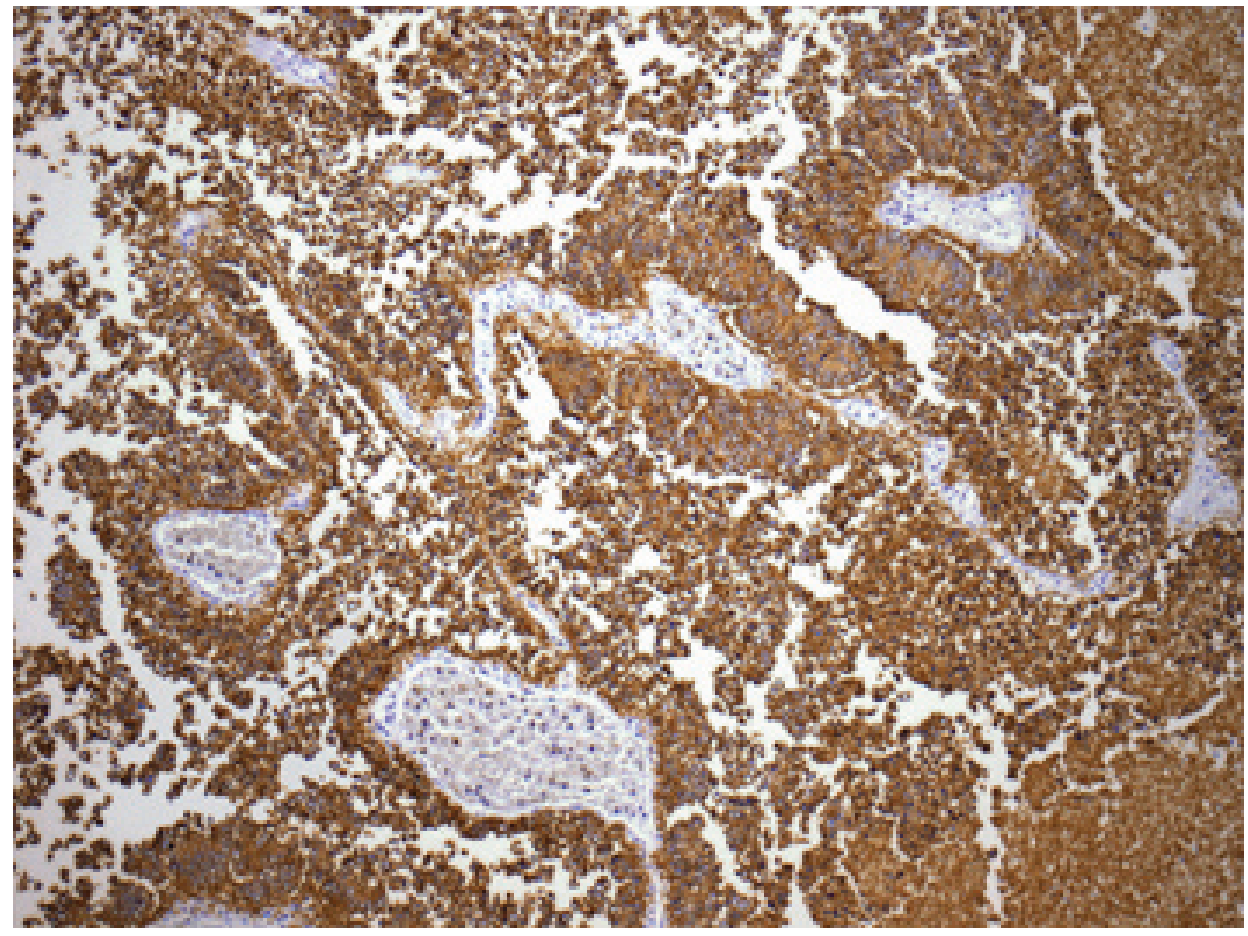

Figura 11 - Fotomicrografia (IHQ - 100X) - Exame imuno-histoquímico da neoplasia difusamente positivo para o anticorpo monoclonal Ber-EP4. 
Os anticorpos para os receptores de estrógeno e progesterona resultaram negativos, entretanto, considerando-se que estudos mostram positividade variável à partir de $50 \%$ (estrógeno) e de $60 \%$ (progesterona), o resultado negativo pode ser atribuído à necrose maciça, e não exclui a origem endometrial/ovariana da neoplasia, que neste caso mostra aspecto histopatológico endometrióide e seroso papilífero típicos, inclusive com corpos psamomatosos (calcificações concêntricas). A ausência de disseminação retroperitoneal pode ser atribuída, neste caso, à circunscrição neoplásica pela espessa cápsula fibrosa (fibroses repetidas de origem cicatricial) característica dos cistos endometrióticos. A causa terminal do óbito foi atribuída à septicemia com focos pulmonar (broncopneumonia) e intra-abdominal (peritonite por deiscência da anastomose em Y de Roux). Em decorrência do choque séptico foram observados ainda: focos hemorrágicos no encéfalo, gastrite hemorrágica, necrose tubular aguda renal e dano alveolar difuso (pulmão de choque).

\section{DISCUSSÃO}

Uma das questões centrais atualmente é se o câncer de ovário associado à endometriose é uma doença distinta, ou se apresenta comportamento igual ao câncer de ovário não relacionado à doença. ${ }^{11}$ Estudos têm documentado a progressão da endometriose, como doença benigna, para o câncer. Entretanto, o mecanismo desta transformação ainda não é conhecido. ${ }^{12}$ Por sua vez, o critério diagnóstico da endometriose associada ao câncer de ovário é heterogêneo, variando entre os trabalhos publicados. Enquanto alguns autores consideram como diagnóstico a evidência de transformação maligna em glândulas de focos de endometriose, outros incluem casos onde foi observada a transformação de um foco de endometriose para um foco de carcinoma. ${ }^{11}$

Kobayashi et al. ${ }^{13}$ verificaram que a taxa de incidência de câncer de ovário é cerca de 9 vezes maior em mulheres com endometrioma de ovário, comparada às não portadoras da doença. A taxa de incidência aumenta com a idade, chegando a ser 13 vezes maior em mulheres com endometrioma diagnosticados acima dos 50 anos. Por outro lado, no caso aqui relatado o câncer desenvolveuse de cisto endometriótico extra ovariano.

Modesitt et al. $^{2}$, em estudo retrospectivo com mulheres que apresentaram câncer intraperitoneal associado à endometriose, verificaram que as mulheres com câncer extra ovariano que se originaram de focos endometrióticos apresentavam maior chance de estarem na menopausa e de fazerem uso da terapia hormonal (TH). Nesse grupo, os tipos histológicos mais comumente encontrados foram os tumores de células claras e endometrióides ( $23 \%$ cada), tumores epiteliais mistos $(19 \%)$ e adenocarcinomas serosos (18\%). No caso relatado, foi verificada a presença de padrões endometrióide e seroso-papilífero, podendo ser considerado como um adenocarcinoma epitelial misto, em concordância com o descrito na literatura.

Uma das possíveis explicações para essa transformação maligna do foco de endometriose é decorrente de defeitos genéticos. Wiegand et al. ${ }^{14}$ relataram a mutação do gene ARID1A em $46 \%$ dos carcinomas de ovário de células claras e em $30 \%$ dos endometrióides. Em duas pacientes com endometriose atípica, verificou-se também a mutação desse gene no foco de endometriose contíguo ao tumor, mas não nos focos distantes. Esse conceito é reforçado pelo trabalho de Jiang et al. ${ }^{15}$, os quais evidenciaram lesões genéticas comuns aos carcinomas de células claras e endometrióides com os focos de endometriose adjacentes às neoplasias, bem como naqueles que originaram os carcinomas, sugerindo que os padrões endometrióide e de células claras podem ser originários da transformação maligna dos focos de endometriose.

Apesar da possível origem de alguns tipos do câncer ovariano relacionado à endometriose, verificou-se que as neoplasias de ovário relacionadas à endometriose parecem apresentar um prognóstico mais favorável, com melhores taxas de sobrevida, provavelmente relacionadas com a maior prevalência de lesões diagnosticadas em estágio precoce, bem como pelo baixo grau destes tumores. ${ }^{11}$

Empenha-se esforço na tentativa de se fazer o diagnóstico precoce do câncer ovariano, mas até o momento não existe o método adequado de rastreamento populacional desta doença. Por sua vez, a RM é o método de imagem mais usado para avaliação da endometriose pélvica profunda, podendo ter sensibilidade superior a $90 \%$ na capacidade de predição de lesões malignas. ${ }^{1,16}$ Nesses casos, as imagens sugestivas de acometimento neoplásico são a presença de massa unilateral cística com focos de hemorragia e nódulos murais com realce ao contraste. ${ }^{17}$ 


\section{CONCLUSÃO}

A transformação carcinomatosa da endometriose é evento relativamente raro, pouco compreendido e de ainda difícil diagnóstico pelos métodos atuais. Não há até o momento orientação para seguimento ou rastreamento da transformação maligna nos focos de endometriose.

\section{REFERÊNCIAS}

1. Coutinho Junior AC, Lima CMAO, Coutinho EPD, Ribeiro EB, Aidar MN, Nassar M, Gasparetto EL. Ressonância magnética na endometriose pélvica profunda: ensaio iconográfico. Radiol Bras. 2008;41:129-34.

2. Modesitt SC, Tortolero-Luna G, Robinson JB, Gershenson DM, Wolf JK. Ovarian and extraovarian endometriosis-associated cancer. Obstet Gynecol. 2002;100:788-95.

3. Olive DL, Pritts EA. Treatment of endometriosis. N Engl J Med. 2001;345:266-75.

4. Jimbo H, Yoshikawa H, Onda T, Yasugi T, Sakamoto A, Taketani Y. Prevalence of ovarian endometriosis in epithelial ovarian cancer. Int J Gynaecol Obstet. 1997;59:245-50.

5. Heaps JM, Nieberg RK, Berek JS. Malignant neoplasms arising in endometriosis. Obstet Gynecol. 1990;75:1023-8.

6. Brinton LA, Lamb EJ, Moghissi KS, Scoccia B, Althuis MD, Mabie JE, et al. Ovarian cancer risk associated with varying causes of infertility. Fertil Steril. 2004;82:405-14.

7. Kobayashi H, Sumimoto K, Kitanaka T. Ovarian endometrioma: risk factors of ovarian cancer development. Eur J Obstet Gynecol Reprod Biol. 2008;138:187-93.

8. Grauy LA, Barnes ML. Relation of endomeriosis to Carcinoma of the ovary. Ann Surg. 1966;163:713-24.

9. Nagle CM, Olsen CM, Webb PM, Jordan SJ, Whiteman DC, Green AC; Australian Cancer Study Froup. Endometrioid and clear cell ovarian cancers: a comparative analysis of risk factors. Eur J Cancer. 2008;44:2477-84.

10. Ordónez NG.Value of Immunohistochemistry in Distinguishing Peritoneal Mesothelioma from Serous Carci-

\section{AGRADECIMENTOS}

Os autores agradecem a Rosa Maria da Conceição Zanardi pelo auxílio na documentação das imagens apresentadas. noma of the Ovary and Peritoneum. Adv Anat Pathol. 2006;13:16-25.

11. Kumar S, Munkarah A, Arabi H, Bandyopadhyay S, Semaan A, Hayek K, et al. Prognostic analysis of ovarian cancer associated with endometriosis. Am J Obstet Gynecol. 2011;204:e1-7.

12. Nezhat F, Datta MS, Hanson V, Pejovic T, Nezhat C. The relationship of endometriosis and ovarian malignancy: a review. Fertil Steril. 2008;90:1559-70.

13. Kobayashi H, Sumimoto K, Moniwa N, Imai M, Takakura $\mathrm{K}$, Kuromaki T, et al. Risk of developing ovarian cancer among women with ovarian endometrioma: a cohort study in Shizuoka, Japan. Int J Gynecol Cancer. 2007;17:37-43.

14. Wiegand KC, Shah SP, Al-Agha OM, Zhao Y, Tse K, Zeng $T$, et al. ARID1A mutations in endometriosis-associated ovarian carcinomas. N Engl J Med. 14;363:1532-43.

15. Jiang X, Morland SJ, Hitchcock A, Thomas EJ, Campbell IG. Allelotyping of endometriosis with adjacent ovarian carcinoma reveals evidence of a common lineage. Cancer Res. 1998;15;58:1707-12.

16. Takeuchi M, Matsuzaki K, Uehara H, Nishitani H. Malignant transformation of pelvic endometriosis : MR imaging finding and pathologic correlation. Radiografics. 2006;26:407-17.

17. Tanaka YO, Yoshizako T, Nishida M, Yamaguchi M, Sugimura K, Itai Y. Ovarian carcinoma in patients with endometriosis: MR imaging findings. Am J Roentgenol. 2000;175:1423-30.

\section{Conflito de interesses: Não}

Autor correspondente: João Augusto dos Santos Martines

Submetido em: 13 de Maio de 2011

Aceito em: 30 de Maio de 2011

\section{Correspondência:}

Av. Prof. Lineu Prestes, 2565 - Cidade Universitária - São Paulo - SP - Brasil

CEP: 05508-000 - Tel.: +55.11. 3091.9309

E-mail: jasmartines@gmail.com 